\title{
Manual Aspiration Technique to Retrieve a Prematurely Detached Coil during Cerebral Aneurysm Embolization
}

\author{
David A. Stidd, MD, MS, Andrew K. Johnson, MD, Demetrius K. Lopes, MD
}

Coil herniation, premature deployment, and fracture are procedure associated complications of endovascular aneurysm embolization that optimally necessitate coil retrieval when feasible. Several published techniques describe different strategies for managing coil complications including various snare retrieval devices, alligator retrieval devices, stent fixation, and open surgical resection of coils when distal blood flow is compromised. We report a novel technique employed to retrieve a prematurely detached coil during an aneurysm embolization using a syringe fixed to the microcatheter to carefully aspirate a loose coil with direct fluoroscopic visualization. This technique can only be utilized in the circumstance where the proximal end of the coil remains in the microcatheter. Conventional techniques of coil retrieval and stenting are discussed and compared to the rational for using the manual aspiration technique.

Key Words : Cerebral aneuryusms; Endovascular procedures/complication; Embolization, therapeutic

The indications for endovascular treatment of intracranial vascular pathologies continue to expand as new techniques and technologies evolve. This in turn has increased both the number of endovascular procedures performed and a proportional number of procedure related complications, including coil stretching, unraveling, prolapse, and migration. The reported

\footnotetext{
All authors: Department of Neurosurgery, Rush University Medical Center, Chicago, IL, USA

Received October 10, 2013; accepted after revision November 24 2013.

Correspondence to: Demetrius K. Lopes, MD, Rush University Medical Center, 1725 W. Harrison Street, Suite 855, Chicago, Illinois 60612, USA

Tel. 1.312.563.3394 Fax. 1.312.942.2176

E-mail: brainaneurysm@mac.com

This is an Open Access article distributed under the terms of the Creative Commons Attribution Non-Commercial License (http://creativecommons.org/licenses/by-nc/3.0) which permits unrestricted non-commercial use, distribution, and reproduction in any medium, provided the original work is properly cited.
}

incidence of coil stretching is less than $2 \%$ and only $0.5 \%$ for coil protrusion and migration $[1,2]$. Despite the rare incidence of these coil complications, these events represent a challenge to manage. Loose coil ends significantly contribute to thromboembolic events, increasing risk of ischemic stroke and permanent neurologic deficit [3]. There are currently several devices and published technique strategies to retrieve loose coils. Each technique, however, is limited to specific complications and thus have limited efficacy.

We describe an alternative to these salvage strategies that may serve as a simple, elegant retrieval strategy in the limited situation where a Penumbra Coil 400 (Penumbra, Alameda, CA, USA) detaches prematurely inside of the PX 400 microcatheter (Penumbra, Alameda, CA, USA). In this specific situation, a stretched and detached coil trapped inside of a coil mass may be successfully retrieved using careful aspiration under direct fluoroscopic visualization. A case illustration using this aspiration technique is 
presented.

\section{TECHNICAL REPORTS}

A 59-year-old female with hypertension and a family history significant for intracranial aneurysms presented for evaluation of an incidental basilar tip aneurysm found after a workup for dementia. The aneurysm had a maximum diameter of $11.8 \mathrm{~mm}$ and a $5.8 \mathrm{~mm}$ neck (Fig. 1). The patient was ultimately consented for an elective stent-assisted coil embolization of the aneurysm. On the day of the procedure, the patient was sedated and intubated without complication and her right femoral artery was accessed. Her intracranial vascular anatomy was characterized with digital subtraction angiography. Through a $6 \mathrm{~F}$ Neuron guide catheter (Penumbra, Alameda, CA, USA) placed into the left vertebral artery, a Prowler Select Plus microcatheter (Codman Neurovascular Inc, Bridgewater, NJ, USA) was navigated into the left posterior cerebral artery. A $4.5 \times 22 \mathrm{~mm}$ Enterprise stent (Codman Neurovascular Inc, Miami, FL, USA) was deployed across the neck of the aneurysm from the left P1 segment to the basilar artery. The aneurysm was then accessed with a 0.025 inch inner diameter PX400 microcatheter with a standard microwire through the struts of the stent and a Penumbra Coil 400 coil was deployed, framing the aneurysm dome. A second coil was passed through the same microcatheter in an attempt to fill the aneurysm, but only half of the coil could be inserted into the dome without causing coil loop prolapse. The microcatheter fell out of the aneurysm, but the distal end of the coil remained trapped in the coil mass. Attempts to completely deploy the coil into the aneurysm were unsuccessful. After attempts to retrieve the coil, it eventually prematurely detached from the pusher wire, leaving the proximal portion of the partially deployed coil still inside the microcatheter.

At this point of the procedure, options of placing a second stent to secure the loose coil end against the vascular lumen or using a snare to attempt coil retrieval were considered. As an alternative, the PX400 microcatheter was detached from continuous flush and the pusher wire was withdrawn. A $20 \mathrm{~mL}$ syringe was then fixed to the microcatheter and with careful aspiration under fluoroscopic visualization; the detached coil was retrieved through the microcatheter, disengaging it from aneurysm coil mass without disruption (Fig. 2). The loose coil was clearly visualized inside of the hub of the microcatheter after the aspiration retrieval (Fig. $3)$. Subsequent coils were delivered into the microcatheter, occluding the aneurysm without further complication. No contrast extravasation was appreciated during the procedure and the patient's neurologic exam afterward was unchanged relative to her examination prior to the procedure.
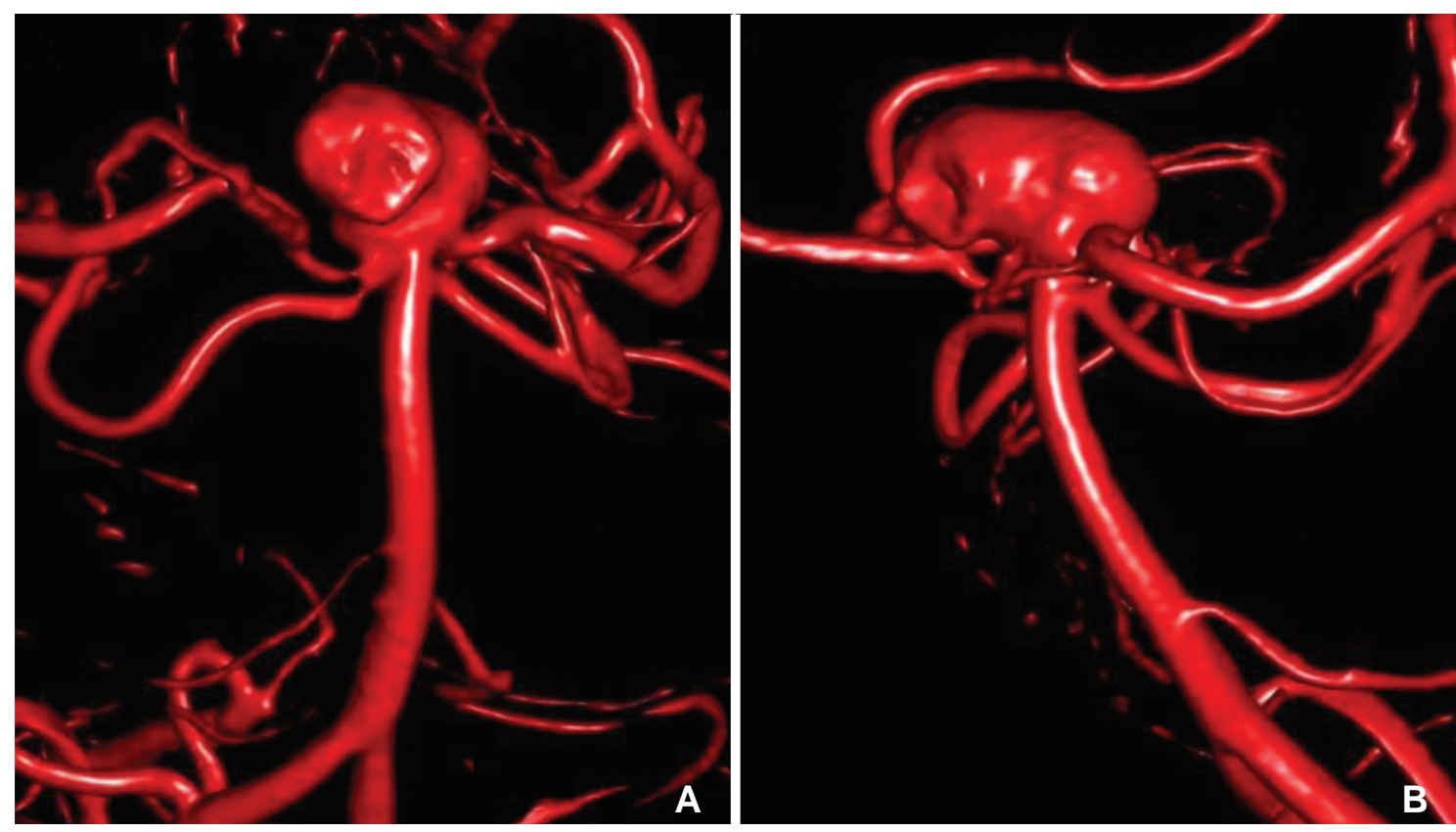

Fig. 1. Anterior-posterior (A) and lateral (B) 3D reconstruction views of a digital subtraction angiogram depicting an incidentally discovered basilar tip aneurysm. 


\section{Aspiration Retrieval of Detached Coil}

\section{DISCUSSION}

Premature coil detachment occurs when a pusher wire is no longer connected to a coil during an embolization procedure. Despite the varied coil detachment mechanisms available, including mechanical, hydraulic, electrothermal, and the classic electrolytic, premature detachment continues to be a potential technical complication, though its occurrence is rare. Excessive force applied to a coil through repeated coil deployments or navigation through tortuous vascular anatomy increases the chance of premature detachment [4]. If a coil partially deployed into an aneurysm prematurely detaches while inside of the delivery catheter, that is if the proximal end of the coil remains in the microcatheter, then the disconnected pusher wire may be still be used to completely deploy the coil into the aneurysm. In the case illustration presented, this was attempted, but the remaining portion of the coil was not accepted into the coil mass within the aneurysm without microcatheter kick back outside of the aneurysm. In this situation, salvage strategies must be considered to avoid the potential complications of a loose coil including distal embolization, ischemic stroke, and permanent neurologic deficit.

A coil that prematurely detaches from a pusher wire while completely outside the delivery microcatheter is a
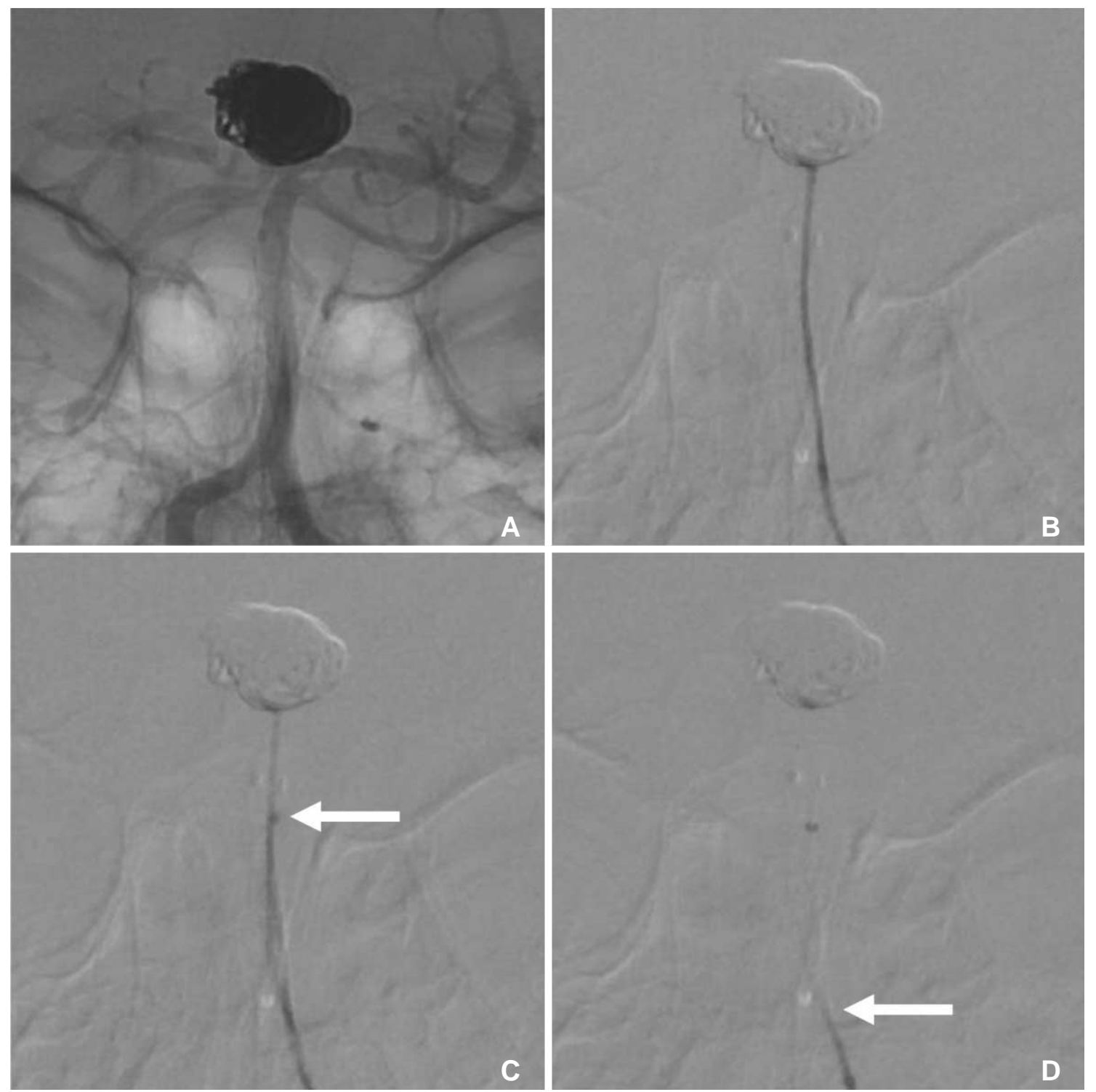

Fig. 2. A. Anterior-posterior fluoroscopic view of the basilar tip aneurysm filled with a coil mass. B-D. Sequential fluoroscopy frames showing release of the detached, partially deployed coil from the coil mass during aspiration through the PX400 microcatheter. The white arrows identify the distal end of the loose coil. 


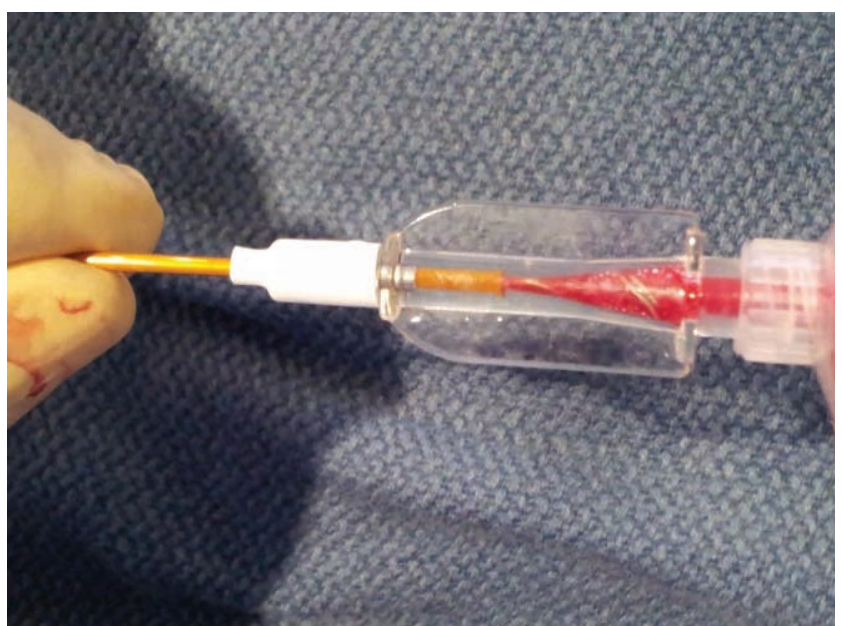

Fig. 3. Syringe connected to the PX400 microcatheter depicting the prematurely detached coil within the catheter hub after aspiration retrieval.

difficult problem to manage since control over the coil is lost completely. The proximal portion of the coil in this situation is a loose end and the entire coil may be loose if the distal end was not yet partially delivered into a coil mass. There are several published strategies to manage this situation. First, stents have been deployed over loose coil ends, securing the loose ends against the lumen with favorable success in limited cases [5-8]. Balloon remodeling techniques have also been described were a balloon is placed at the base of the aneurysm neck, compacting the coil mass inside the aneurysm and assisting the placement of a prolapsed coil loop back into the aneurysm [4, 9]. Several types of snares and alligator clamps are also available to retrieve loose, detached coils [4, 10-12]. However, the risks of coil retrieval using these devices, thromboembolism and damage to the intima for example, must be weighed against the risks of other management strategies. Capturing a loose coil with a snare is very difficult maneuver and typically contralateral groin access is required. A technique using a balloon to stabilize a coil mass while a snare was used to retrieve a loose coil has been described [13]. Several reports describe an alternative strategy to retrieve a loose coil using the Merci Retrieval System (Concentric Medical, Inc., Mountain View, CA, USA) [14-16] or thrombectomy stent devices $[17,18]$. Ultimately, if attempts at retrieval of a loose coil are unsuccessful in the presence of compromised distal blood flow, open surgical procedures have been used to remove displaced coils [19-23].

Some control over a coil is retained when the proximal end of a prematurely detached coil remains inside of the delivery microcatheter. It may be possible to complete the deployment of a coil that was partially deployed into an aneurysm in this circumstance, particularly if the position of the microcatheter remains inside the aneurysm despite the fact the pusher wire is no longer physically attached to the coil. In addition to the salvage strategies available for a proximal coil end that was prematurely detached outside of the delivery catheter, a prematurely detached proximal coil end that is retained in a microcatheter offers more retrieval strategies. The delivery microcatheter, for instance, can be used as a guide to slide a snare down to and around the loose coil end [24]. A strategy for wedging the loose coil end inside of the microcatheter using guidewires has been described [25]. $\mathrm{Ng}$ et al. described retrieving a prematurely detached coil that remained inside of a microcatheter using a vacuum inside of the microcatheter created by rapidly withdrawing the pusher wire [26]. It has also been suggested that a vacuum can be created to retrieve a loose coil in this manner by attaching a syringe to the hub of the microcatheter [4], though this technique has not been published. We report the successful application of this technique to retrieve a prematurely detached coil that partially remained inside of the delivery microcatheter.

The design features of the Penumbra Coil 400 used in the case illustration may have aided the aspiration retrieval of the coil. This coil has a relatively larger primary diameter and thin inner filament wire, making the coil very pliable and soft. We postulate that the combination of coil softness and larger size may have enabled the complete aspiration retrieval of this coil through the microcatheter. The microcatheter inner diameter and the coil size allow for a minimal free space between them. This creates an optimal seal allowing for increased vacuum power during manual aspiration. The coil softness and vacuum created from the tight fit contributed for such a dramatic migration of the coil from the aneurysm to the aspirating syringe on the hub of the microcatheter. We have not tested the manual aspiration coil retrieval method with different types of coils and microcatheters. This technique was helpful on this case because the PX 400 microcatheter was inside of a $6 \mathrm{~F}$ guide catheter. This leaves no room for our preferred method of coil retrieval using the microcatheter as a guide to slide a snare down to and around the loose coil end [24]. The technique described allowed for a very simple bail out from a potentially difficult situation.

In conclusion, premature coil detachment is a difficult complication to manage and significantly 


\section{Aspiration Retrieval of Detached Coil}

contributes to thromboembolic events, thus requiring either retrieval or fixation of the prolapsed coil. Optimal salvage strategies must be tailored to the specific situation and the experience of the interventionist. We describe an effective, safe technique for retrieving a prematurely detached Penumbra coil that remains in the delivery microcatheter.

\section{References}

1. Murayama Y, Nien YL, Duckwiler G, Gobin YP, Jahan R, Frazee J, et al. Guglielmi detachable coil embolization of cerebral aneurysms: 11 years' experience. J Neurosurg 2003;98:959-966

2. Cognard C, Weill A, Castaings L, Rey A, Moret J. Intracranial berry aneurysms: angiographic and clinical results after endovascular treatment. Radiology 1998;206:499-510

3. Derdeyn CP, Cross DT, 3rd, Moran CJ, Brown GW, Pilgram TK, Diringer MN, et al. Postprocedure ischemic events after treatment of intracranial aneurysms with Guglielmi detachable coils. $J$ Neurosurg 2002;96:837-843

4. Eddleman CS, Welch BG, Vance AZ, Rickert KL, White JA, Pride GL, et al. Endovascular coils: properties, technical complications and salvage techniques. J Neurointerv Surg 2013;5:104109

5. Chung J, Kim YB, Hong CK, Joo JY, Shin YS, Lim YC. Stent salvage using the Enterprise stent for procedure-related complication during coil embolization of ruptured intracranial aneurysms. Acta Neurochir (Wien) 2013;155:223-229

6. Luo CB, Chang FC, Teng MM, Guo WY, Chang CY. Stent management of coil herniation in embolization of internal carotid aneurysms. AJNR Am J Neuroradiol 2008;29:1951-1955

7. Schutz A, Solymosi L, Vince GH, Bendszus M. Proximal stent fixation of fractured coils: technical note. Neuroradiology 2005;47:874-878

8. Wong GKC, Yu SCH, Wong K-T, Poon W-S. Stent salvage for parent vessel coil herniation during intracranial aneurysm embolization. Surgical Practice 2009;13:114-118

9. Sugiu K, Martin JB, Jean B, Rufenacht DA. Rescue balloon procedure for an emergency situation during coil embolization for cerebral aneurysms. Technical note. J Neurosurg 2002;96:373376

10. Lampmann LE, Sluzewski M, Van Rooij WJ. Retrieval of malpositioned, dislocated or fractured guglielmi detachable coils from intracranial vessels. A report of seven cases. Interv Neuroradiol 2000;6:251-256

11. Koseoglu K, Parildar M, Oran I, Memis A. Retrieval of intravascular foreign bodies with goose neck snare. Eur J Radiol 2004;49: 281-285

12. Henkes H, Lowens S, Preiss H, Reinartz J, Miloslavski E, Kuhne D. A new device for endovascular coil retrieval from intracranial vessels: alligator retrieval device. AJNR Am J Neuroradiol 2006;27:327-329

13. Dinc H, Kuzeyli K, Kosucu P, Sari A, Cekirge S. Retrieval of prolapsed coils during endovascular treatment of cerebral aneurysms. Neuroradiology 2006;48:269-272

14. Kung DK, Abel TJ, Madhavan KH, Dalyai RT, Dlouhy BJ, Liu $\mathrm{W}$, et al. Treatment of endovascular coil and stent migration using the merci retriever: report of three cases. Case Rep Med 2012;2012:242101

15. O'Hare A, Brennan P, Thornton J. Retrieval of a Migrated Coil Using an X6 MERCI Device. Interv Neuroradiol 2009;15:99-102

16. Vora N, Thomas A, Germanwala A, Jovin T, Horowitz M. Retrieval of a displaced detachable coil and intracranial stent with an L5 Merci Retriever during endovascular embolization of an intracranial aneurysm. J Neuroimaging 2008;18:81-84

17. Hopf-Jensen S, Hensler HM, Preiss M, Muller-Hulsbeck S. Solitaire(R) stent for endovascular coil retrieval. J Clin Neurosci 2013;20:884-886

18. Leslie-Mazwi TM, Heddier M, Nordmeyer H, Stauder M, Velasco A, Mosimann PJ, et al. Stent retriever use for retrieval of displaced microcoils: a consecutive case series. AJNR Am J Neuroradiol 2013;34:1996-1999

19. Heuer GG, Zaghloul KA, Roberts R, Stiefel MF, Storm PB. Successful microsurgical extraction of a migrated coil in a pediatric patient after failed endovascular closure of a BlalockTaussig shunt. Case report. J Neurosurg 2007;106(Suppl 2):136138

20. Kojima T, Miyachi S, Negoro M, Nakabayashi K, Fukui K, Takahashi I, et al. Coil retrieval following embolization of cerebral aneurysms. Interv Neuroradiol 2003;9(Suppl 1):149-155

21. Raftopoulos C, Goffette P, Billa RF, Mathurin P. Transvascular coil hooking procedure to retrieve an unraveled Guglielmi detachable coil: technical note. Neurosurgery 2002;50:912-914

22. Shin YS, Lee KC, Kim DI, Lee KS, Huh SK. Emergency surgical recanalisation of A1 segment occluded by a Guglielmi detachable coil. J Clin Neurosci 2000;7:259-262

23. Thornton J, Dovey Z, Alazzaz A, Misra M, Aletich VA, Debrun GM, et al. Surgery following endovascular coiling of intracranial aneurysms. Surg Neurol 2000;54:352-360

24. Fiorella D, Albuquerque FC, Deshmukh VR, McDougall CG. Monorail snare technique for the recovery of stretched platinum coils: technical case report. Neurosurgery 2005;57(Suppl 1):E21

25. Standard SC, Chavis TD, Wakhloo AK, Ahuja A, Guterman LR, Hopkins LN. Retrieval of a Guglielmi detachable coil after unraveling and fracture: case report and experimental results. Neurosurgery 1994;35:994-998

26. Ng PP, Halbach VV, Caragine LP, Dowd CF, Higashida RT. Guglielmi detachable coil extraction: suction generated by pusherwire withdrawal after coil detachment within an intracranial aneurysm. AJNR Am J Neuroradiol 2003;24:982-984 